$16^{\text {th }}$ International Congress of Metrology, 10006 (2013)

DOI: $10.1051 /$ metrology/201310006

(c) Owned by the authors, published by EDP Sciences, 2013

\title{
THE FIRST KEY COMPARISON Of PRIMARY STANDARD GAS MIXTURE of the BRAZILIAN NATIONAL METROLOGY INSTITUTE
}

\author{
A.L. Fioravante $^{1}$, C. R. Augusto ${ }^{1}$, E.C.S. Elias ${ }^{1}$, M.C. Brum ${ }^{1}$, D.C.G.S. Teixeira ${ }^{1}$, C.C. Ribeiro ${ }^{1}$, R.J. Oudwater ${ }^{1}$, F.A. \\ Fagundes ${ }^{1}$, M.C. da Silva ${ }^{1}$ and R.G. Reis ${ }^{1}$ \\ ${ }^{1}$ Inmetro, Brazil
}

\begin{abstract}
The growing requirements concerning the accuracy of measurements and their traceability and worldwide comparability constitute a considerable challenge for Brazilian National Metrology Institute, Inmetro, with its responsibility for ensuring the scientific background for the consistency and accuracy of national measurements. This paper reports the results of the first participation of Inmetro in the international key comparison (KC) of primary standard gas mixture (PSM) of automotive emission gravimetric production. This participation aims to fulfil the necessary preliminary criteria for mutual recognition of measurements, and the results obtained were considered satisfactory..
\end{abstract}

\section{Introduction}

Nowadays, quality in gas analysis has increased, requiring international standards of comparison. Nevertheless, in Brazil there is a lack of availability of primary reference gas mixtures (PRM), what leads to the importation of these certified reference materials (CRM). The production of these standards intends to avoid the importation needs and substantially decrease its costs, in order to include Brazil in the selected group of national producers of PRM. The automotive emission PRM is the first developed CRM that Inmetro produced, in order to support the demand of national gas industry and to disseminate traceability among the society.

This report describes the key comparison on PSMs (primary standard gas mixtures) for "automotive" gas mixtures between national metrology institutes (NMIs) under auspices of the Euramet [1].

The capabilities for the gravimetric preparation of such $\mathrm{CRM}$, that is gas mixture of carbon monoxide (CO), carbon dioxide (CO2), and propane (C3) in nitrogen (N2) matrix, have been compared, with participating NMI submitting each a gravimetrically prepared gas mixture of a specified target composition typical for the automotive industry to the coordinating laboratory. The measurement of this PRM is relevant for implementing regulations with regard to car exhaust gas measurements.

Inmetro's mixture submitted was consistent with respect to the key comparison reference value (KCRV) for all components. The results from the final report presented satisfactory relative agreement within 10-2 mol mol-1 of the reference values for all the components in the gas mixture. The report was submitted to the JCRB (Joint Committee of the Regional Metrology Organizations and BIPM) after approval of the CCQM Gas Working Group. Therefore, Inmetro's participation has successfully validated its preparation capabilities for this 4 (four)

\footnotetext{
a Corresponding author: author@email.org
}

component primary reference gas mixture. It is also expected that future activities on gas analysis regarding development of gas mixtures CRMs will further improve in the harmonization and optimization of measurement methods and the reduction of measurement uncertainty.

\section{Methodology}

\subsection{Field of measurement and Subject}

This comparison was performed to quantify and compare among the participants the amount-of-substance fraction of gas mixtures for car exhaust measurements, automotive mixtures with the following nominal composition: 20 mmol mol-1 carbon monoxide, 120 mmol mol-1 carbon dioxide, and $1000 \mu \mathrm{mol}$ mol-1 propane in nitrogen.

\subsection{Participants}

In total, 5 (five) participants joined this $\mathrm{KC}$ and were requested to prepare the automotive mixture. In this key comparison the participants submitted a PSM to the coordinating laboratory. Table 1 presents the participating NMI laboratories and their respective country.

Table 1 - Participants

\begin{tabular}{|c|c|}
\hline NMI Laboratory & Country \\
\hline INMETRO & Brazil \\
\hline IPQ & Portugal \\
\hline VSL & The Netherlands \\
\hline SMU & Slovakia \\
\hline NMISA & South Africa \\
\hline
\end{tabular}




\subsection{Measurement protocol}

The calculation of the gas composition and associated uncertainty evaluation should be done in accordance with ISO 6142:2001 [2]. This produced mixture was verified by the Brazilian laboratory using Varian 3800sp gas chromatograph equipped with these columns: a WCOT Fused silica $(60 \mathrm{~m} \times 0,25 \mathrm{~mm})$, a Hayesep $\mathrm{T}(0,5 \mathrm{~m} \times$ $2 \mathrm{~mm})$, a Hayesep Q $(0,5 \mathrm{~m} \times 2 \mathrm{~mm})$ and a Molsieve $13 \mathrm{x}$ (1,5m x 2mm); Helium (5.0) was used as carrier gas, and the $\mathrm{GC}$ has a thermal conductivity detector (TCD) for the $\mathrm{CO}$ and $\mathrm{CO} 2$ analysis and a flame ionization detector (FID) for the propane analysis, which were performed in three runs under repeatability conditions. Based on the calibration curve, analysis values and its respective uncertainties were assigned to the amount fractions of carbon monoxide, carbon dioxide, and propane using the ISO 6143:2001 [3].

The submitted reference gas mixtures were measured three times against VSL PSMs (primary standard gas mixtures) on three different days. The reference values for the amount-of-substance fractions are obtained by interpolation using the calibration curve. The measurements from the coordinating Laboratory were taken on an Agilent $6890 \mathrm{~N}$ gas chromatograph equipped with a $10 \mathrm{ft}$ Porapak $\mathrm{N}$ and a $3 \mathrm{ft}$ Molsieve 13x column, and two detectors (flame ionisation detector (FID) and thermal conductivity detector (TCD)). Helium (5.0) was used as carrier gas. For all components, the TCD signal was used.

\subsection{Measurement calculation}

The prepared reference gas mixture was measured against PRMs on 03 (three) different days. The reference values for the amount-of-substance fractions are obtained by interpolation using a calibration curve. The results that follow are presenting the uncertainty of the area, with 07 (seven) repetitions, for each day, during 03 (three) days. The results from the gas chromatographic measurements have been fitted using a quadratic polynomial function, in accordance with ISO 6143:2001, using the software bleast.

Standard uncertainty of the mixture was calculated with following formula:

$$
u_{\text {cert }}=\sqrt{u_{\text {prep }}^{2}+u_{v e r}^{2}+u_{s t}^{2}}
$$

where:

ucert final uncertainty

uprep uncertainty of gravimetric preparation uver uncertainty from verification (GC analysis) ust uncertainty from stability (not done)

\subsection{Degree-of-Equivalence}

A degree of equivalence is defined as the difference of a measurement result with respect to the key comparison reference value (KCRV) [4,5]:

$$
d_{i}=x_{i}-x_{\text {KCRV }}
$$

and its associated uncertainty. In previous key comparisons where the participating laboratories submitted a mixture, the KCRV was calculated from the consensus straight line obtained from calibrating the analyser with the submitted mixtures [6,7]. This approach is in this key comparison not possible, because of the very limited ranges of the components. As alternative approach the analyser is calibrated with the PSMs (Primary Standard gas Mixtures) from the coordinating laboratory. In this case the analysed value of the amountof-substance fraction is adopted as KCRV:

$$
x_{\text {KCRV }}=x_{\mathrm{o}}
$$

for each component in each mixture.

The uncertainty of the degree-of-equivalence defined by equations (2) and (3) is given by equation (4):

$$
u\left(d_{i}\right)=\sqrt{u^{2}\left(x_{i}\right)+u^{2}\left(x_{\text {KCRV }}\right)}
$$

which follows directly from the application of the law of propagation of uncertainty to equation (2).

\section{Results}

\subsection{Gravimetry}

The automotive mixture was gravimetrically prepared by Inmetro's Gas Analysis Laboratory in accordance to the ISO 6142:2001. The mixture was filled 120 bar in a 5L aluminium cylinder from Scott, which a special surface treatment. It was used a pre-mix of $\mathrm{CO}$ and another one of propane, both from VSL, with their purity table declared by the NMI. The pure CO2 quality $9999.9 \%$ and N2 quality $99999.9 \%$ were used, and their purity table was estimated based on the supplier information, in accordance to the ISO 6142:2001. The purity table for the final mixture of interest gravimetrically prepared is presented in Table 2 .

Table 2 - Gravimetric results

\begin{tabular}{|c|c|c|}
\hline Component & $\begin{array}{c}\text { Molar Fraction } \\
\text { (mol/mol) }\end{array}$ & $\begin{array}{c}\text { Uncertainty } \\
\text { (mol/mol) }\end{array}$ \\
\hline $\mathrm{CH}_{4}$ & 0.0000000017 & 0.0000000009 \\
\hline $\mathrm{N}_{2}$ & 0.8589528168 & 0.0000056786 \\
\hline $\boldsymbol{C}_{3} \boldsymbol{H}_{\boldsymbol{8}}$ & $\mathbf{0 . 0 0 1 0 0 1 2 7 9 1}$ & $\mathbf{0 . 0 0 0 0 0 0 2 4 8 8}$ \\
\hline $\mathrm{Ar}$ & 0.0000012499 & 0.0000005484 \\
\hline $\boldsymbol{C O}$ & $\mathbf{0 . 0 1 9 9 7 4 8 0 2 0}$ & $\mathbf{0 . 0 0 0 0 0 1 5 5 4 2}$ \\
\hline $\boldsymbol{C} \boldsymbol{O}_{2}$ & $\mathbf{0 . 1 2 0 0 6 8 7 9 5 3}$ & $\mathbf{0 . 0 0 0 0 0 5 3 1 7 2}$ \\
\hline $\mathrm{C}_{2} \mathrm{H}_{6}$ & 0.0000000105 & 0.0000000003 \\
\hline $\mathrm{H}_{2}$ & 0.0000000753 & 0.0000000354 \\
\hline $\mathrm{H}_{2} \mathrm{O}$ & 0.0000003739 & 0.0000001385 \\
\hline $\mathrm{O}_{2}$ & 0.0000004730 & 0.0000001910 \\
\hline $\mathrm{C}_{\mathrm{x}} \mathrm{H}_{\mathrm{y}}$ & 0.0000001123 & 0.0000000413 \\
\hline $\mathrm{C}_{3} \mathrm{H}_{6}$ & 0.0000000100 & 0.0000000030 \\
\hline
\end{tabular}




\subsection{Verification}

\subsubsection{Carbon Monoxide}

The results for the carbon monoxide GC analysis, including the calibration curve using the PRMs from VSL, are presented in Table 3 and Table 4.

Table 3 - Calibration curve for CO

\begin{tabular}{|c|c|c|c|c|}
\hline Mixture & $\begin{array}{c}\text { Grav. Conc. } \mathbf{x} \\
\left(\mathbf{m m o l ~ m o l}^{\mathbf{1}} \mathbf{)}\right.\end{array}$ & $\begin{array}{c}\mathbf{u}(\mathbf{x}) \\
(\mathbf{m m o l} \\
\mathbf{m o l}^{-\mathbf{1}} \mathbf{)}\end{array}$ & $\begin{array}{c}\mathbf{G C} \\
\text { area (y) }\end{array}$ & $\mathbf{u ( y )}$ \\
\hline A & 10.015 & 0.010 & 35820.619 & 84.138 \\
\hline B & 23.960 & 0.025 & 86717.095 & 151.653 \\
\hline C & 30.080 & 0.045 & 111781.342 & 198.003 \\
\hline D & 49.940 & 0.050 & 182429.238 & 300.357 \\
\hline E & 80.650 & 0.100 & 294937.143 & 492.443 \\
\hline
\end{tabular}

It's important to observe that those results are already from the average of the 3 (three) days of analysis.

Table 4 - CO verification results $\left(\mathrm{mmol} \mathrm{mol}^{-1}\right)$

\begin{tabular}{|l|l|}
\hline Verification concentration & 19.902 \\
\hline Verification uncertainty & 0.055 \\
\hline Certificate concentration & $\mathbf{1 9 . 9 7 0}$ \\
\hline Final uncertainty $(\boldsymbol{k}=\mathbf{2 , 9 5 \% )}$ & $\mathbf{0 . 1 1}$ \\
\hline
\end{tabular}

The results regarding the degree-of-equivalence calculated by the coordinating laboratory considering only the results sent by Inmetro are presented in Table 5 and Figure 1.

Table 5 - Differences in DoE uncertainty for CO from Inmetro $\left(\mathrm{mmol} \mathrm{mol}{ }^{-1}\right)$

\begin{tabular}{|l|l|}
\hline $\mathrm{x}_{\mathrm{KCRV}}$ & 19.985 \\
\hline $\mathrm{u}\left(\mathrm{x}_{\mathrm{KCRV}}\right)$ & 0.005 \\
\hline $\mathbf{d}$ & $\mathbf{- 0 . 0 1 5}$ \\
\hline $\mathbf{u}(\mathbf{d})$ & $\mathbf{0 . 0 5 6}$ \\
\hline
\end{tabular}

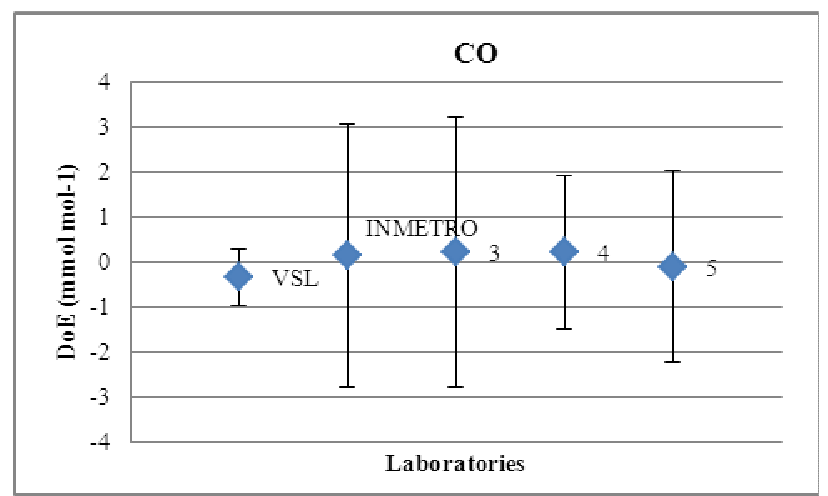

Figure 1. Differences in DoE for CO

\subsubsection{Carbon Dioxide}

The results for the carbon dioxide $\mathrm{GC}$ analysis, including the calibration curve using the PRMs from VSL, are presented in Table 6 and Table 7.

Table 6 - Calibration curve for $\mathrm{CO}_{2}$ *

\begin{tabular}{|c|c|c|c|c|}
\hline Mixture & $\begin{array}{c}\text { Grav. } \\
\text { Conc. } \mathbf{x} \\
\text { (mmol }_{\text {mol }^{-1} \text { ) }}\end{array}$ & $\begin{array}{c}\mathbf{u}(\mathbf{x}) \\
(\mathbf{m m o l} \\
\mathbf{m o l}^{-1} \text { ) }\end{array}$ & GC area (y) & $\mathbf{u ( y )}$ \\
\hline A & 35.97 & 0.035 & 145859.571 & 226.662 \\
\hline B & 50.11 & 0.075 & 203253.714 & 472.071 \\
\hline C & 79.89 & 0.125 & 324933.619 & 927.191 \\
\hline D & 99.97 & 0.10 & 407947.714 & 631.227 \\
\hline E & 117.48 & 0.12 & 480066.238 & 780.812 \\
\hline F & 139.84 & 0.14 & 572630.762 & 924.761 \\
\hline G & 149.80 & 0.25 & 613990.476 & 1578.245 \\
\hline
\end{tabular}

*average of the 3 (three) days of analysis.

Table 7 - CO2 verification results (mmol mol-1)

\begin{tabular}{|l|l|}
\hline Verification concentration & 120.05 \\
\hline Verification uncertainty & 0.26 \\
\hline Certificate concentration & $\mathbf{1 2 0 . 0 7}$ \\
\hline Final uncertainty $(\boldsymbol{k}=\mathbf{2 , 9 5 \% )}$ & $\mathbf{0 . 2 6}$ \\
\hline
\end{tabular}

The results regarding the degree-of-equivalence calculated by the coordinating laboratory considering only the results sent by Inmetro are presented in Table 8 and Figure 2.

Table 8 - Differences in DoE uncertainty for $\mathrm{CO} 2$ from Inmetro (mmol mol-1)

\begin{tabular}{|l|l|}
\hline $\mathrm{x}_{\mathrm{KCRV}}$ & 120.06 \\
\hline $\mathrm{u}\left(\mathrm{x}_{\mathrm{KCRV}}\right)$ & 0.04 \\
\hline $\mathbf{d}$ & $\mathbf{0 . 0 1}$ \\
\hline $\mathbf{u}(\mathbf{d})$ & $\mathbf{0 . 2 6}$ \\
\hline
\end{tabular}

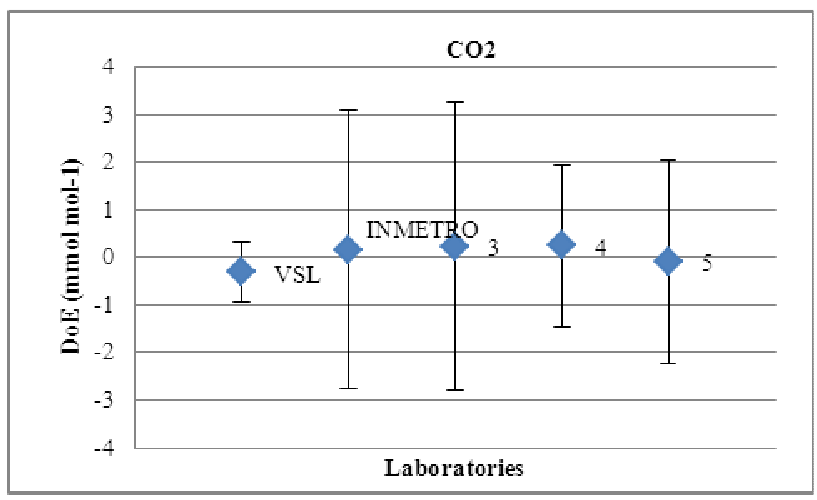

Figure 2. Differences in DoE for $\mathrm{CO} 2$ 


\subsubsection{Propane}

The results for the propane $\mathrm{GC}$ analysis, including the calibration curve using the PRMs from VSL, are presented in Table 9 and Table 10.

Table 9 - Calibration curve for $\mathrm{C} 3$ *

\begin{tabular}{|c|c|c|c|c|}
\hline Mixture & $\begin{array}{c}\text { Grav. } \\
\text { Conc. } \mathbf{x} \\
(\boldsymbol{\mu m o l} \\
\left.\mathbf{m o l}^{-1}\right)\end{array}$ & $\begin{array}{c}\mathbf{u}(\mathbf{x}) \\
(\boldsymbol{\mu m o l} \\
\left.\mathbf{m o l}^{-1}\right)\end{array}$ & $\begin{array}{c}\text { GC } \\
\text { area }(\mathbf{y})\end{array}$ & $\mathbf{u}(\mathbf{y})$ \\
\hline A & 599.6 & 1.2 & 263227.476 & 871.757 \\
\hline B & 961.5 & 1.8 & 422461.667 & 1115.677 \\
\hline C & 1449.0 & 0.3 & 638490.429 & 1415.692 \\
\hline D & 2004.0 & 3.0 & 885668.000 & 2151.632 \\
\hline E & 2473.0 & 5.0 & 1096010.810 & 2381.657 \\
\hline F & 3203.0 & 5.0 & 1420630.429 & 1954.504 \\
\hline G & 3486.0 & 7.5 & 1548147.571 & 2933.780 \\
\hline
\end{tabular}

*average of the 3 (three) days of analysis.

Table $10-\mathrm{C} 3$ verification results $(\mu \mathrm{mol}$ mol-1)

\begin{tabular}{|l|l|}
\hline Verification concentration & 1000.83 \\
\hline Verification uncertainty & 2.87 \\
\hline Certificate concentration & $\mathbf{1 0 0 1 . 3 0}$ \\
\hline Final uncertainty $(\boldsymbol{k}=\mathbf{2 , 9 5 \% )}$ & $\mathbf{2 . 8 8}$ \\
\hline
\end{tabular}

The results regarding the degree-of-equivalence calculated by the coordinating laboratory considering only the results sent by Inmetro are presented in Table 11 and Figure 3.

Table 11 - Differences in DoE uncertainty for C3 from Inmetro ( $\mu \mathrm{mol}$ mol-1)

\begin{tabular}{|l|l|}
\hline $\mathrm{x}_{\mathrm{KCRV}}$ & 1001.14 \\
\hline $\mathrm{u}\left(\mathrm{x}_{\mathrm{KCRV}}\right)$ & 0.45 \\
\hline $\mathbf{d}$ & $\mathbf{0 . 1 6}$ \\
\hline $\mathbf{u}(\mathbf{d})$ & $\mathbf{2 . 9 2}$ \\
\hline
\end{tabular}

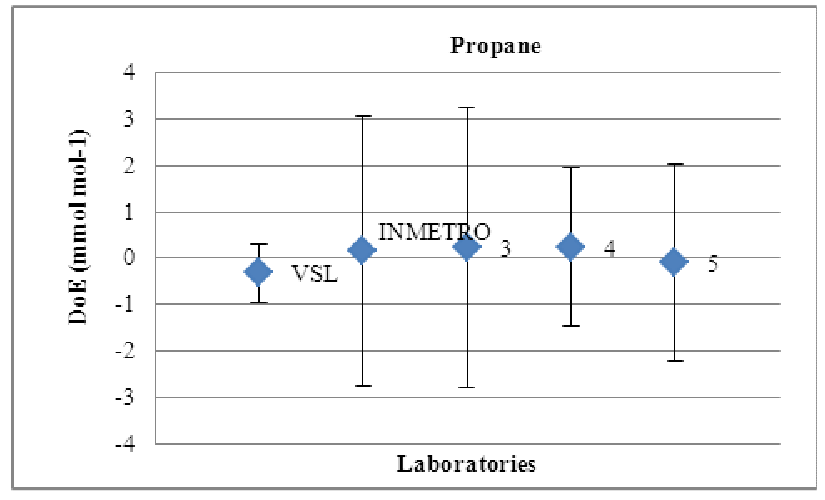

Figure 3. Differences in DoE for Propane

\section{Conclusions}

The gravimetrically prepared mixture of automotive emission submitted is consistent with respect to the key comparison reference value (KCRV) for all components (carbon monoxide, carbon dioxide and propane in nitrogen). Inmetro as well as the other participating laboratories has therefore successfully validated their preparation capabilities for this 4 (four)-component gas mixture.

Therefore, the results of DoE for Inmetro, i.e. the difference between the gravimetric concentration and the analythical concentration obtained by the KCRV, are very satisfactory for all components. This demonstrates that Inmetro has the capacity of producing gas mixtures by the gravimetry method in accordance to the Standard ISO 6142:2001, obtaining results with quality equivalent to known National Metrology Institutes in the gas area. For future goals of this type of mixture the Laboratory intends to prepare a whole range for each component of this gas mixture and certify it until the first semester of 2013, besides obtaing the CMC for this mixture, in order to put available this CRM with confident levels to society. The results of the certification of the prepared range of PSMs are going to be presented during the event Metrologie 2013.

\section{References}

1. Final Report of EURAMET QM-S4 - Key comparison automotive gas mixture, VSL, September 2011.

2. International Organization for Standardization, ISO 6142:2001 Gas analysis - Preparation of calibration gas mixtures - Gravimetric methods, 2nd edition

3. International Organization for Standardization, "ISO 6143 - Gas analysis -- Comparison methods for determining and checking the composition of calibration gas mixtures", ISO Geneva, 2001

4. Cox M.G., "The evaluation of key comparison data: An introduction", Metrologia 39 (2002), pp. 587-588

5. Cox M.G., "The evaluation of key comparison data", Metrologia 39 (2002), pp. 589-595

6. Jeongsoon Lee, Jin Bok Lee, Dong Min Moon, Jin Seog Kim, Van der Veen A.M.H., Besley L., Heine H.J., Martin B., Konopelko L.A., Kato K., Shimosaka T., Perez Castorena A., Macé T., Milton M.J.T., Kelley M., Guenther F., Botha A., "Final report on international key comparison CCQM-K53: Oxygen in nitrogen”, Metrologia 47 (2010), Tech. Suppl., 08005

7. Van der Veen A.M.H., Chander H., Ziel P.R., Wessel R.M., de Leer E.W.B., Smeulders D., Besley L., Kato K., Watanabe T., Seog Kim J., Woo J-C., Kil Bae H., Doo Kim Y., Pérez Castorena A., Rangel Murillo F., Serrano Caballero V.M., Ramírez Nambo C., Avila Salas M.d.J., Konopelko L.A., Popova T.A., Pankratov V.V., Kovrizhnih M.A., Kuzmina T.A., Efremova O.V., Kustikov Y.A., M.J.T.Milton, Vargha G., Guenther F.R. and Rhoderick G.C., "International comparison CCQM-K54: Primary standard gas mixtures of hexane in methane", Metrologia 47 (2010), Tech. Suppl., 08019 